\title{
Expression of Emotional Intelligence Among Tennis Players
}

\author{
Audronė Dumčienė, Saulė Bilevičienė, Beatričè Sipavičiūtė \\ Lithuanian Sports University, Kaunas, Lithuania
}

\begin{abstract}
Background. Emotional intelligence (EI) is most commonly studied based on the cognitive-emotional ability or trait emotional self-efficacy model (Siegling \& Petrides, 2015). This study was based on the EI capability model. Research based on ability models measures a person's ability to solve emotional problems and assesses the ability to perform emotion-related tasks (Magrum, Waller, Campbell, \& Schempp, 2019). The aim of this study was to reveal the expression of emotional intelligence in tennis players.

Methods. To collect data, Schutte SSRI questionnaire survey was applied. Research participants were 99 tennis payers (55 men and 44 women, aged 15 to 65 years), including 85 amateurs and 15 professional players.

Results. The comparison of mean scores for emotional intelligence according to gender showed that women had a statistically significantly higher score in other people's emotion management $(3.8 \pm 0.44)$ than men $(3.6 \pm$ $0.49)(t(97)=-2.116 ; p=.037)$. Age comparisons of emotional intelligence scores revealed a statistically significant better estimate among tennis players over the age of $41(4.24 \pm 0.53)$ than those under the age of $30(3.78 \pm 0.7)$ $(p=.008)$. There were also statistically significant positive weak relationships between tennis player age and emotion utilization ( $r=.269 ; p=.007)$ and overall emotional intelligence rating $(r=.211 ; p=.036)$. There were no statistically significant differences between the aspects of emotional intelligence in training duration $(p>.05)$.

Conclusions. It was found that women believed they were better able than men to manage other people's emotions, and the difference between women's and men's opinions was statistically significant $(p<.05)$. Statistically significant positive correlations were revealed between the age of tennis players and the use of emotions $(p<.01)$ as well as age and the general assessment of emotional intelligence $(p<.05)$. This study did not reveal a significant relationship between the emotional intelligence of tennis players and the duration of training $(p>.05)$.
\end{abstract}

Keywords: tennis players, emotional intelligence, abilities.

\section{INTRODUCTION}

$\mathrm{T}$ The expression of emotional intelligence (EI) in professional activities and sports has been of interest to many researchers (Clark, 2016; Kopp \& Jekauc, 2018; Laborde, Dosseville, \& Allen, 2015; Magrum et al., 2019; Nozaki, 2015; Pursun \& Efilti, 2019; Ubago-Jiménez, GonzálezValero, Puerto-Molero, \& Garcia-Martínez, 2019). It has been revealed (Kaup \& Jekauc, 2018) that EI has a positive effect on athletes' performance and may also be related to stress management or the athletes' own motivation to play sport (UbagoJiménezet al., 2019). EI is most commonly studied based on the cognitive-emotional ability or trait emotional self-efficacy model (Siegling \& Petrides, 2015). We will base this study on the EI abilities model.

The abilities-based EI model was proposed and improved by Salovey and Mayer (1990, 1997), Mayer, Caruso, and Salovey (2016). Solovey and Mayer (1990, p. 189) defines the EI as follows: "We define emotional intelligence as the subset of social intelligence that involves the ability to monitor one's own and others' feelings and emotions, to discriminate among them and to use this 
information to guide one's thinking and actions". Mayer and Salovey (1997) distinguished four areas of EI expression: optimism, social skills, appraisal, and utilization. In the additional EI description (Mayer, Caruso, \& Salovey, 2016) psychological processes were presented, starting from basic to superior, more psychologically integrated processes based on seven newly formulated principles. In a hierarchical order, from the ability to perceive and express basic emotions to the abilities associated with conscious and thoughtful regulation of emotions. Early emotional abilities are usually weakly integrated with each other; later abilities develop in a more integrated adult personality. People with high EI are expected to have developed the highest emotional abilities and are able to master them more (Mayer \& Salovey, 1997).

Research based on EI ability models measures person's ability to solve emotional problems and evaluate the ability to perform emotion-related tasks (Magrum et al., 2019). The results of a study conducted by Bahrololoum, Hassani, Bandeli, and Akbari (2012) showed a relationship between emotional intelligence and attention concentration. Thus, emotions help to draw a persons' attention to the desired area. The ability to recognize emotions depends on concentration. Since emotions are based on sensory information as EI increases, so does the level of self-awareness increase resulting in a greater attention concentration. A person with a higher level of EI can better organize his/ her thoughts, memory, and information in memory and better focus by organizing his/her thoughts and thinking (Bahrololoum et al., 2012).

Laborde et al., (2015) found that EI is associated with physiological responses to stress, successful use of psychological skills, and more successful athletic performance. Athletes with higher EI test scores are more successful. EI influences sportrelated variables, including psychological skills, coaching, athletes' performances, and same factors beyond sport (Magrum et al., 2019). EI has a positive effect on self-confidence, psychological resilience and reduction of pre-competition anxiety. This is especially necessary because probably the most important ability of athletes is their capacity to play sports (participate in a competition). The ability to identify, understand and manage emotions also plays a key role (Magrum et al., 2019). Trigueros, Aguilar-Parra, Álvarez, Gonz ález-Bernal, and López-Liria (2019) believe that EI in professional athletes positively predicts self-esteem and self-determined motivation, and negatively predicts anxiety. Furthermore, it was noted that EI is an element of psychological resilience.

Zarei, Zandi, and Mahmoud (2018) argue that psychological resilience is one of the most important multiple mental skills influencing athletic success. It is also very important to understand the factors that influence the development of EI for the athlete. The results of the study showed that the EI training intervention had a significant effect on psychological resilience and its components (selfconfidence, consistency, and control). Emotional intelligence training can be useful and effective tool to improve the psychological resilience of elite athletes (Zarei et al., 2018). The results of a study by Arribas-Galarraga, Saies, Cecchini, Arruza, and Luis-De-Cos (2017) suggest that emotional intelligence can act as a mediator between selfmotivation and performance success. In other words, intrinsically motivated athletes are able to better regulate their emotions, which in turn has a positive impact on their outcomes (Magrum et al., 2019). Singh and Sachdev (2020) found that individuals with high levels of general and emotional intelligence experience lower-intensity stress, and it is important that chronic stress can develop in response to acute stress over a long period of time. The authors recommend that moderate-intensity exercises can improve general intelligence and cognitive functions such as short-term memory and concentration. Moderate intensity exercises also help prevent emotional exhaustion due to better emotional regulation. The results of the Cowden's (2016) study showed that EI significantly predicted psychological toughness, and psychological toughness mediated the relationship between EI and coping effectiveness among well-performing male athletes engaged in a variety of sports.

EI education for athletes is relevant and possible because, as the results of the study by Kotsou, Mikolajczak, Heeren, Gregoire, and Leys (2018) shows, indicators of subjects who underwent the intervention improved, compared to the control groups. This is confirmed by the results of a study conducted by Hodzic, Scharfen, Ripoll, Holling, and Zenasni (2017), which suggest that EI training is an effective intervention that improves EI in the long term.

EI evaluated by a self-report emotional abilities questionnaires shows the degree to which individuals consider themselves capable, meaningful, successful, and worthy (Marsh, 
1996). Self-report of emotional abilities is a multifaceted aspect and should be assessed in the light of the fact that the level of human competence may vary in different areas of life. A person can underestimate their abilities and performance. A properly self-assessed person objectively evaluates his/her abilities and possibilities by comparing them with the requirements of the environment. An independent statement of the emotional abilities of such individuals can be close to reality. Self-determination theory argues that a correct and authentic statement of emotional abilities is stable and assured when people are vibrant, fully functional, and motivated when all their basic psychological needs are met (Ryan \& Deci, 2004). However, when a self-report about emotional abilities is a concern for people and basic psychological needs are not met or balanced, the self-report of emotional abilities can become defensive.

Hypothesis - female tennis players have higher emotional intelligence than male tennis players.

The study is based on the self-definition theory (Deci \& Ryan, 2000; Ryan \& Deci, 2000) which reveals three main human psychological needs (competence, autonomy and relatedness) and the expression of emotional intelligence on the basis of ability (Salovey \& Mayer, 1990; Mayer et al., 2016).

\section{METHODS}

Research participants. The sample consisted of 99 tennis payers (55 men and 44 women, aged 15 to 65 years, including 85 amateurs and 15 professional players). The EI components of the players were selected as the dependent variables of the research object, while gender, age and training duration were selected as independent variables. An online link to a questionnaire (the questionnaire was filled in via www.apklausa.lt) was published on a social network of tennis players' groups. Such organization of a survey protected the anonymity of the research participants.

Instruments. The Schutte Self-Report Inventory (Schutte, Malouff, \& Bhullar, 2009) was employed for tennis players' emotional abilities evaluation. The SSRI comprises 33 items, covering four areas with sub-scales: perception of emotions, managing one's emotions, managing other people's emotions, and using emotions, which the respondent needs to evaluate by using a Likert 5 -point scale, where 1 means "strongly disagree" and 5 - "strongly agree". This is one of the most commonly used self-assessment tests to evaluate the EI (Laborde et al., 2015). The Lithuanian version of the SSRI shows an internal consistency value of 0.79 and a test-retest reliability coefficient of 0.84 for the overall questionnaire (Malinauskas \& Vazne, 2014; Akelaitis \& Malinauskas, 2018)

Statistical analysis. SPSS-22.0 for Windows software package was used for data processing. The Kolmogorov-Smirnov test was used to check the normality of the variables, and the Shapiro-Wilk test was used for smaller sample groups. Given the test results and the values of asymmetry and excess, the assumption of normality was partially satisfied (as indicated by George and Mallery (2010), if the coefficients of excess and asymmetry are in the range of -2 to 2 , it is acceptable to consider the section slightly away from normal). Analysing the distributions of the scale variables, it was found that the distributions of all variables were not significantly distant from the normal distribution, therefore parametric criteria were chosen for the analysis. To check the reliability of the emotional intelligence scales, their internal compatibility indicators (Cronbach's alpha) were calculated. The consistency of the statements in the whole questionnaire was found to be very good, as the Cronbach's alpha was equal to .881 and for the individual subscales it ranged from .652 to .811 . In terms of age, three age groups were distinguished - less than 30 years, 31-40 years and more 40 years, and training durations - one and less, from two - four, five - seven, eight - ten and more 10 years. Student's t-test was used for comparisons of means between gender groups, and ANOVA analysis with Post-Hoc tests was used for means of age and training duration groups. The Spearman's correlation coefficient $r$ was calculated to determine the relationships. Significance level $p<.05$ was adopted in the analysis.

\section{RESULTS}

The tennis players' EI components' estimates by gender are shown in Table.

A one-way analysis of variance was performed between subjects by ANOVA to compare the effect of age on EI components in age groups less than 30 years, $31-40$ years, and more than 41 years. For three conditions, the significant effect of age on the EI component of emotion utilization $(p<.05)$ was $[F(2,99)=4.722, p=.011]$. Past Hoc comparisons 
Table. Tennis players' EI components estimates by gender (scores)

Note. ${ }^{*} p<.05$

\begin{tabular}{|c|c|c|c|c|c|}
\hline EI components & Gender & Mean & $S D$ & $\begin{array}{l}\text { Student } t \text {-test } \\
\quad(d f)=97\end{array}$ & $p$ \\
\hline \multirow{2}{*}{ Perception of emotions } & Men & 3.73 & 0.44 & \multirow{2}{*}{-1.147} & \multirow{2}{*}{.254} \\
\hline & Women & 3.84 & 0.51 & & \\
\hline \multirow{2}{*}{ Managing one's emotions } & Men & 4.00 & 0.42 & \multirow{2}{*}{0.818} & \multirow{2}{*}{.416} \\
\hline & Women & 3.93 & 0.46 & & \\
\hline \multirow{2}{*}{$\begin{array}{l}\text { Managing other people's } \\
\text { emotions }\end{array}$} & Men & 3.60 & 0.49 & \multirow{2}{*}{-2.116} & \multirow{2}{*}{$.037 *$} \\
\hline & Women & 3.80 & 0.44 & & \\
\hline \multirow{2}{*}{ Using emotions } & Men & 3.90 & 0.69 & \multirow{2}{*}{-1.444} & \multirow{2}{*}{.152} \\
\hline & Women & 4.09 & 0.60 & & \\
\hline \multirow{2}{*}{ Overall assessment of EI } & Men & 3.80 & 0.38 & \multirow{2}{*}{-1.249} & \multirow{2}{*}{.215} \\
\hline & Women & 3.90 & 0.38 & & \\
\hline
\end{tabular}

using the Tukey HSD test showed that the average emotional utilization component estimate $(M=4.24$, $S D=0.53)$ for tennis players over 41 years of age differed significantly from the average emotional utilization component estimate for tennis players under 30 years of age $(M=3.78, S D=0.70)$.

However, when comparing other aspects of EI, no statistically significant differences were found $(p>.05)$, so we can say that tennis players of different age groups evaluated emotion perception, their emotion management and other people's emotion management, other than the use of emotions, quite similarly.

The results of the Spearman's correlation analysis revealed statistically significant positive correlations between the age of tennis players and the use of emotions $(r=.269, p=.007)$ and the overall assessment of emotional intelligence $(r=.211, p=.036)$. We can say that the older the age of tennis players, the better their use of emotions is valued and the higher their overall emotional intelligence is valued.

Comparing aspects of EI according to training duration using ANOVA with Post-Hoc tests and comparison of means, no statistically significant differences were found ( $p>.05$ ), so we can say that tennis players of different training duration groups evaluated emotion perception and emotion management, managing other people's emotions and using emotions quite similarly. Spearman's correlation analysis revealed that tennis players' emotional intelligence was not statistically significantly related to training duration $(p>.05)$.

To predict the change in emotional intelligence with increasing age of tennis players, the regression equation $Y=3.551 *+0.009 *$ (age (years)) was derived, where * - statistically significant coefficients of the equation $(p<.05)$.

\section{DISCUSSION}

The results of this study only partially confirmed the hypothesis of the study that the EI of female tennis players was higher than that of male tennis players. Women self-rated only one of EI components other people's emotion management better than men $(p<.05)$, although there was a tendency for women's scores to be higher than those of men, except for the component of emotion management which was higher in men. Our results are consistent with Yücel and Özdayi's (2019) observation that women recognize and regulate the emotions of others better than men. It has been revealed that the emotion management of team sports athletes is better than that of individual sports athletes. Team sports help individuals to socialize more easily, to communicate better with people, to stand firm in defeat, to build team spirit, and to collaborate (Yücel \& Özdayi, 2019). Our study revealed higher overall EI scores for women than for men, although the difference was insignificant. Similar results were obtained by Schutte et al. (1998). Can (2016) found that women volleyball players had higher rates of EI than men in all components. Although there are studies that have not found significant gender difference in the analysis of EI in different disciplines (Badawy \& Magdy, 2015; Nikbakhsh, Nourollahi, Mirzaei, \& Rahimi, 2014).

In our study, it was found that the use of emotions was statistically significantly better evaluated by tennis players older than 41 years than by those younger than 30 years $(p<.01)$. However, 
no statistically significant differences were found for other EI components $(p>.05)$.

Other studies confirm our findings that older individuals have higher rates of EI aspects (Gardner \& Qualter, 2011; Tsaousis \& Kazi, 2013; Viegas \& Kamble, 2014)). The results of a study by Badawy and Magdy (2015) showed that the relationship between age and EI was also positive. Our study found statistically significant positive correlations between the age of tennis players and the use of emotions $(r=.269, p=.01)$, and the overall selfassessment of EI $(r=.211, p<.05)$. We can say that the older the age of tennis players, the better their use of emotions is valued and the higher their overall EI is valued.

In our study, EI showed no statistically significant differences in training duration $(p>.05)$. Similar results were obtained by ArribasGalarraga et al. (2017), who observed that the EI of rowers remains relatively stable regardless of years of practice. Peña-Sarrionandia, Mikolajczak, and Gross (2015) point out that individuals with high EI successfully regulate their emotions when needed, and they do it flexibly, leaving space for emotions to emerge and express. A review of the literature by Grigoriou, Vasiliki, Tachias, Gilyana, and Bougiesi (2012) suggests that EI in older people is higher, suggesting that EI components may be evolving and may develop over time. Johnson (2015) argues that the concept of EI as an ability-based model can be adopted and assumes that EI can be developed as specific competencies which could be applied in a particular area. So, EI and its components that are relevant to a particular activity can be developed (Gorgas, Greenberger, Bahner, \& Way, 2015). Therefore, when developing various competencies of tennis players, coaches should also focus on the athletes' EI.

Since tennis can be both an individual sport and a team sport, and studies show that EI aspects are more correlated in team sports (CastroSánchez, Zurita-Ortega, Chacón-Cuberos, LópezGutiérrez, \& Zafra-Santos, 2018), further research is recommended depending on whether the subject is playing alone or in pairs with a partner because verbal and non-verbal communication between partners is important (Samulski, 2006).

\section{CONCLUSIONS}

1. It was found that women believed they could manage other people's emotions better than men and the difference between women's and men's opinions is statistically significant $(p<.05)$.

2. Statistically significant positive correlations were revealed between the age of tennis players and the use of emotions $(p<.01)$ as well as age and the general assessment of emotional intelligence $(p<.05)$.

3. This study did not find a significant relationship between the emotional intelligence of tennis players and the duration of training $(p>.05)$.

\section{REFERENCES}

Akelaitis, A., \& Malinauskas, R. K. (2018). The expression of emotional skills among individual and team sports male athletes. Pedagogics, Psychology, MedicalBiological Problems of Physical Training and Sports, 22(2), 62-67. doi: 10.15561/18189172.2018.0201

Arribas-Galarraga, S., Saies, E., Cecchini, J. A., Arruzik J. A., \& Luis-De-Cos, I. (2017). The relationship between emotional intelligence, self-determined motivation and performance in canoeists. Journal of Human Sport and Exercise, 12(3), 630-639. doi: 10.14198/jhse.2017.123.07

Badawy, T. A. E., \& Magdy, M. M. (2015). Assessing the impact of emotional intelligence on job satisfaction: An empirical study on faculty members with respect to gender and age. International Business Research, 8(3), 67-78. doi: 10.5539/ibr.v8n3p67

Bahrololoum, H., Hassani, A., Bandeli, M. R., \& Akbari, A. (2012). The Relationship between the emotional intelligence and mental skills in Iranian elite male volleyball players. International Journal of Academic Research in Business and Social Sciences, 2(7), 123-130.

Can, S. (2016). Can emotionally intelligent volleyball players be more prone to sportspersonship? Journal of Education and Training Studies, 4(7), 54-60. doi: 10.11114/jets.v4i7.1447

Castro-Sánchez, M., Zurita-Ortega, F., ChacónCuberos, R., López-Gutiérrez, C., \& Zafra-Santos, E. (2018). Emotional intelligence, motivational climate and levels of anxiety in athletes from different categories of sports: Analysis through structural equations. International Journal of Environmental Research and Public Health, 15(5), 894. doi: 10.3390/ ijerph15050894

Clark, R. (2016). Intelligence analysis: A target-centric approach. London: CQ Press. 
Cowden, R. G. (2016). Mental toughness, emotional intelligence, and coping effectiveness: An analysis of construct interrelatedness among high-performing adolescent male athletes. Perceptual and Motor Skills, 123(3), 737-753. doi: 10.1177/0031512516666027

Deci, E. L., \& Ryan, R. M. (2000). The "what" and "why" of goal pursuits: Human needs and the selfdetermination of behaviour. Psychological Inquiry, 11, 227-268.

Gardner, K. J., \& Qualter, P. (2011). Factor structure, measurement invariance and structural invariance of the MSCEIT V2.0. Personality and Individual Differences, 51(4), 492-496. doi: 10.1016/j.paid.2011.05.004

George, D., \& Mallery, M. (2010). SPSS for Windows Step by Step: A Simple Guide and Reference, 17.0 update (10a ed.) Boston: Pearson.

Gorgas, D., Greenberger, S., Bahner, D., \& Way, D. (2015). Teaching emotional intelligence: A control group of study of a brief educational intervention for emergency medicine residents. Western Journal of Emergency Medicine, 16(16), 899-906. doi: 10.5811/ westjem.2015.8.27304

Grigoriou, S., Vasiliki, Z., Tachias, F., Gilyana, M., \& Bougiesi, M. (2012). emotional intelligence, age and physical activity: Review of contemporary literature. Inquiries in Sport \& Physical Education, 10, 17-29. doi: 10.1080/0361073X.2013.808105

Hodzic, S., Scharfen, J., Ripoll, P., Holling, H., \& Zenasni, F. (2017). How efficient are emotional intelligence trainings: A meta-analysis. Emotion Review, 10(2), 138-148. doi: 10.1177/1754073917708613.

Johnson, D. R. (2015). Emotional intelligence as a crucial component to medical education. International Journal of Medical Education, 6, 179-183. doi: 10.5116/ ijme.5654.3044

Kopp, A., \& Jekauc, D. (2018). The influence of emotional intelligence on performance in competitive sports: A meta-analytical investigation. Sports, 6(4), 175-198. doi: 10.3390/sports6040175

Kotsou, I., Mikolajczak, M., Heeren, A., Gregoire, J., \& Leys, C. (2018). Improving emotional intelligence: A systematic review of existing work and future challenges. Emotion Review, 1-15. doi: 10.1177/1754073917735902.

Laborde, S., Dosseville, F., Guillén, F., \& Chávez, E. (2015). Validity of the trait emotional intelligence questionnaire in sports and its links with performance satisfaction. Psychology of Sport and Exercise, 15(5), 481-490. doi: 10.1016/j.psychsport.2014.05.001

Magrum, E. D., Waller, S., Campbell, S., \& Schempp, P. G. (2019). Emotional intelligence in sport: A ten-year review (2008-2018). International Journal of Coaching Science, 13(2), 3-32. doi: 10.2478/v10197-012-0006-1

Mayer, J. D., Caruso, D. R., \& Salovey, P. (2016). The Ability Model of Emotional Intelligence: principles and updates. Emotion Review, 8(4), 290-300. doi: $10.1177 / 1754073916639667$
Mayer, J. D., \& Salovey, P. (1997). What is emotional intelligence? In P. Salovey \& D. J. Sluyter (Eds.), Emotional development and emotional intelligence: Educational implications (pp. 3-34). New York: Harper Collins. http://ei.yale.edu/wp-content/uploads/2014/02/ pub219_Mayer_Salovey_1997.pdf

Malinauskas, R., \& Vazne, Z. (2014). Emotional intelligence among Lithuanian and Latvian student athletes. Education. Physical Training. Sport, 2 (93), 29-33.

Marsh, H. W. (1996). Positive and negative global self-esteem: A substantively meaningful distinction or artefacts? Journal of Personality and Social Psychology, $70,810-819$.

Nikbakhsh, R., Nourollahi, H., Mirzaei, A., \& Rahimi, M. (2014). Comparison of emotional intelligence on sport coaches. European Journal of Experimental Biology, 4(3), 98-101.

Nozaki, Y. (2015). Emotional competence and extrinsic emotion regulation directed toward an ostracized person. Emotion, 15, 763-774. https://doi.org/f7232x

Peña-Sarrionandia, A., Mikolajczak, M., \& Gross, J. J. (2015). Integrating emotion regulation and emotional intelligence traditions: A meta-analysis. Frontiers in Psychology, 6, 160, 1-27. doi: 10.3389/fpsyg.2015.00160

Pursun, T., \& Efilti, E. (2019). The analysing of the emotional intelligence scores of the special education teacher candidates for the predictor of multiple intelligences areas. European Journal of Educational Research, 8 (2), 409-420. doi: 10.12973/eu-jer.8.2.409

Ryan, R. M., \& Deci, E. L. (2004). Autonomy is no illusion: Self-determination theory and the empirical study of authenticity, awareness, and will. In J. Greenberg, S. L. Koole, \& T. Pyszczynski (Eds.), Handbook of experimental existential psychology (pp. 449-479). New York: The Guilford Press.

Ryan, R. M., \& Deci, E. L. (2000). Self-determination theory and the facilitation of intrinsic motivation, social development, and well-being. American Psychologist, 55(1), 68-78. doi: 10.1037/0003-066x.55.1.68

Salovey, P., \& Mayer, J. D. (1990). Emotional intelligence. Imagination, Cognition, and Personality, 9, 185-211. doi: 0.2190/DUGG-P24E-52WK-6CDG

Samulski, D. (2006). Tennis is a Mental Game - Part One. ITF Coaching and Sport Science Review, 40, 14-15.

Schutte, N. S., Malouff, J. M., \& Bhullar, N. (2009). The Assessing Emotions Scale. Assessing Emotional Intelligence The Springer Series on Human Exceptionality, 119-134. doi: 10.1007/978-0-38788370-0_7

Schutte, N. S., Malouff, J. M., Hall, L. E., Haggerty, D. J., Cooper, J. T., Golden, C. J., \& Dornheim, L. (1998). Development and validation of a measure of emotional intelligence. Personality and Individual Differences, 25(2), 167-177. doi: 10.1016/s01918869(98)00001-4 
Siegling, A. B., \& Petrides, K. V. (2015). Measures of ability and trait emotional intelligence. Measures of Personality and Social Psychological Constructs, 381-414. https://doi. org/10.1016/B978-0-12-386915-9.00014-0

Singh, M., \& Sachdev, S. (2020). Correlation between general intelligence, emotional intelligence and stress response after one-month practice of moderate intensity physical exercise. Journal of Exercise Physiology Online, 23(1), 38-47.

Trigueros, R., Aguilar-Parra, J., Álvarez, J., GonzálezBernal, J. J., \& López-Liria, R. (2019). Emotion, psychological well-being and their influence on resilience. A study with semi-professional athletes. International Journal of Environmental Research and Public Health, 16, 4192. doi: 10.3390/ijerph16214192

Tsaousis, I., \& Kazi, S. (2013). Factorial invariance and latent mean differences of scores on trait emotional intelligence across gender and age. Personality and Individual Differences, 54(2), 169-173. doi: 10.1016/j. paid.2012.08.016

Received on May 05, 2020

Accepted on May 14, 2020
Ubago-Jiménez, J. L., González-Valero, G., PuertasMolero, P., \& Garcia-Martínez, I. (2019). Development of emotional intelligence through physical activity and sport practice: A systematic review. Behavioral Sciences, 9, 44. doi: 10.3390/bs9040044

Viegas, V., \& Kamble, S. V. (2014). As assessment of emotional intelligence and psychological skill usage among professional sports players. Indian Journal of Health and Wellbeing, 5(5), 601-605.

Yücel, A. S., \& Özdayi, N. (2019). Analysis on emotional intelligence levels of physical education and sports students in sports. Universal Journal of Educational Research, 7(3), 853-862. doi: 10.13189/ ujer.2019.070327

Zarei, S., Zandi, H. G., \& Mahmoud, M. (2018). The effectiveness of emotional intelligence training on mental toughness in elite taekwondo athletes. Journal of Development and Motor Learning, 9, 548-563. doi: 10.22059/JMLM.2018.223319.1195 